\title{
Phosphatidylserine eversion regulated by phospholipid scramblase activated by TGF- $\beta 1 /$ Smad signaling in the early stage of kidney stone formation
}

\author{
Xiu Guo Gan ${ }^{1} \cdot$ Hai Tao Xu ${ }^{1} \cdot$ Zhi Hao Wang ${ }^{1}$
}

Received: 24 April 2021 / Accepted: 18 November 2021 / Published online: 3 December 2021

(c) The Author(s) 2021

\begin{abstract}
The mechanism underlying phosphatidylserine eversion in renal tubule cells following calcium oxalate-mediated damage remains unclear; therefore, we investigated the effects of TGF- $\beta 1 /$ Smad signaling on phosphatidylserine eversion in the renal tubule cell membrane during the early stage of kidney stone development. In a rat model of early stage of calcium oxalate stone formation, phosphatidylserine eversion on the renal tubular cell membrane was detected by flow cytometry, and the expression of TGF- $\beta 1$ (transforming growth factor- $\beta 1$ ), Smad7, and phospholipid scramblase in the renal tubular cell membrane was measured by western blotting. We observed that the TGF- $\beta 1 /$ Smad signaling pathway increased phosphatidylserine eversion at the organism level. The results of in vitro studies demonstrated that oxalate exposure to renal tubule cells induced TGF- $\beta 1$ expression, increasing phospholipid scramblase activity and phosphatidylserine eversion in the renal tubule cell membrane. These results indicate that TGF- $\beta 1$ stimulates phosphatidylserine eversion by increasing the phospholipid scramblase activity in the renal tubule cell membrane during the early stage of kidney stone development. The results of this study form a basis for further detailed research on the development of therapeutic agents that specifically treat urolithiasis and exert fewer adverse effects.
\end{abstract}

Keywords Phospholipid scramblase $\cdot$ Phosphatidylserine $\cdot$ Kidney stone $\cdot$ TGF- $\beta 1$

\section{Abbreviations}

PS Phosphatidylserine

ROS Reactive oxygen species

PLSCR Phospholipid scramblase

TGF- $\beta 1 \quad$ Transforming growth factor- $\beta 1$

$\mathrm{CaOx} \quad$ Calcium oxalate

EG Ethylene glycol

Xiu Guo Gan

ganxiuguo@qq.com

Hai Tao Xu

772326609@qq.com

Zhi Hao Wang

2099522695@qq.com

1 Department of Urology, First Affiliated Hospital of Harbin Medical University, Harbin Medical University, Harbin, China

\section{Introduction}

Urolithiasis is one of the most common diseases affecting humans and is associated with multiple urological complications [1]. Calcium oxalate $(\mathrm{CaOx})$ reportedly injures cultured renal tubular cells, after which cell membrane phosphatidylserine (PS) flips from the inner layer to the outer layer in vitro to play important roles in kidney stone formation [2]. Similar findings have been reported by various studies [3-6] conducted at the cellular level. However, the mechanism underlying PS externalization in renal tubule cells caused by $\mathrm{CaOx}$-mediated damage remains unclear. Previous studies have showed that a high concentration of calcium oxalate leads to the overproduction of reactive oxygen species (ROS) [7], which subsequently contributes to PS externalization in renal tubule cells to result in nucleation and growth of $\mathrm{CaOx}$ crystals [8]. ROS and lipid peroxidation strongly activate phospholipid scramblase (PLSCR) [9], whereas exposure to ROS scavengers, such as glutathione, coenzyme Q10, or idebenone (a synthetic coenzyme Q10 homolog), reduces the activation of PLSCR in polycystic kidney disease [10]. PLSCR, which is anchored to the cell 
membrane [11], functions as one of the three phospholipidflipping enzymes capable of catalyzing the rapid two-way movement of PS on both sides of the membrane along a concentration gradient [12]. Under physiological conditions, the cell membrane is in an asymmetric state, and PLSCR has no effect on the membrane [13]. However, following injury of eukaryotic cells, PLSCR is activated and moves PS from the inner to the outer layer [14, 15]. Additionally, overexpression of PLSCR in Chinese hamster ovary K1 cells reportedly stimulates PS externalization, enhancing outward movement of PS to the cell surface during apoptosis [16]. Therefore, we hypothesized that PLSCR is also involved in PS externalization in the renal tubule cell membrane via activation of ROS.

A potential molecular mechanism of oxalate-induced ROS production occurs through induction of TGF- $\beta 1 /$ Smad signaling, which may play a role in the production of ROS $[17,18]$. Indeed TGF- $\beta 1 /$ Smad signaling reportedly is involved a myriad of kidney diseases, such as glomerulonephritis, renal interstitial fibrosis, and nephrolithiasis [19]. Moreover, mononuclear cells treated with TGF- $\beta 1$ exhibit PS externalization in the cell membrane by causing the flipping of PS from the inner to the outer layer [20]. However, to our knowledge, the relationship between TGF- $\beta 1 / \mathrm{Smad}$ signaling and PS eversion in renal tubule cell membranes remains unknown. We hypothesized that TGF- $\beta 1$ participates in PS eversion in renal tubule cell membranes by activating PLSCR in the early stage of rat kidney stone formation mediated by ROS.

Therefore, we investigated whether TGF- $\beta 1 /$ Smad signaling stimulates PS externalization through ROS activation and whether TGF activates PLSCR in the renal tubule cell membrane during the early stage of kidney stone development in vitro and in vivo, thereby laying a theoretical foundation for the etiology of kidney stone formation.

\section{Materials and methods}

\section{Rat model of early stage CaOx kidney stone formation}

Sixty clean 3-month-old male Wistar rats weighing $200 \pm 20 \mathrm{~g}$ were provided by the Experimental Animal Center of Harbin Medical University and housed at room temperature $\left(22{ }^{\circ} \mathrm{C} \pm 2{ }^{\circ} \mathrm{C}\right)$ and $50-70 \%$ humidity. After 3 days of adaptive breeding, they were randomly divided into three groups (20 rats/group)—control, kidney stone, and kidney stone + SB431542 (a TGF- $\beta 1 /$ Smad signaling pathway inhibitor).

Kidney stone formation is initiated as an early pathological change after renal tubular cell injury [21, 22]. To study this process of injury, a rat model of early stage kidney stone formation was established, as a standardized approach has not yet been reported. To observe the early changes after renal tubular cell injury, we applied the method reported by $\mathrm{Li}$ et al. [23]. Briefly, the rats in the control group were administered $2 \mathrm{~mL}$ of distilled water daily via oral gavage, whereas the rats in the kidney stone group were administered $2 \mathrm{~mL}$ of $1 \%$ ethylene glycol solution and $1 \% \mathrm{NH}_{4} \mathrm{Cl}$ solution daily via oral gavage. The rats in the kidney stone + SB431542 group were intraperitoneally injected with SB431542 co-solvent (5 mg/kg, S1067; Selleckchem, Shanghai, China) every 7 days [24]. Food and water were provided ad libitum. On day 14, the rats were euthanized by anesthetic overdose (pentobarbital sodium, $200 \mathrm{mg} / \mathrm{kg}$, via intraperitoneal injection) and their kidneys were excised. The left kidneys were preserved immediately in liquid nitrogen for the subsequent protein detection. The right kidneys were fixed, and then dehydrated and embedded in paraffin wax. All animal studies were conducted according to the National Institutes of Health Guide for the Care and Use of Laboratory Animals. The experimental procedures were approved by the Animal Experiment Use Ethics Committee of the First Affiliated Hospital of Harbin Medical University (Approval number: 2020005, Harbin, China).

\section{Crystal formation in renal tissue}

The tissue samples were stained using Pizzolato method [23] and $\mathrm{CaOx}$ crystals were observe under a polarized light optical microscope (Sinico Optical Instrument Co., Shenzhen, China). Pizzolato-positive regions were measured and expressed as permillages of the total tissue area of crosssections using ImageJ 1.49v (National Institutes of Health, USA).

\section{Detection of PS in renal tubular cell membrane in vivo by flow cytometry}

Renal epithelial cell PS exposure was evaluated using a fluorescein isothiocyanate (FITC)-labeled Annexin V staining assay, as previously described [2]. The cells were observed (in each group) under a confocal laser microscope (Olympus, Tokyo, Japan). The amount of PS externalization was determined as the percentage of Annexin V-positive cells. Annexin $\mathrm{V}$ fluorescence of the samples was measured using a flow cytometer $(488 \mathrm{~nm}$ excitation/530 $\mathrm{nm}$ emission; Beckman Coulter, Brea, CA, USA).

\section{Measurement of TGF- $\beta 1$ and Smad7 levels in renal tubular cell membrane by western blotting}

After recovery of the frozen tissue samples, protein was extracted using the natural membrane protein extraction kit ProteoExtract (M-PEK) (MERCK Co., Kenilworth, NJ, 
USA), and the protein concentration was determined using a Bio-Rad protein assay kit (Hercules, CA, USA) according to manufacturer's instructions. Subsequently, $40 \mu \mathrm{g}$ of protein was loaded on an $8 \%$ SDS-polyacrylamide gel (stacking gel $100 \mathrm{~V}$, resolving gel $200 \mathrm{~V}$ ) for $1 \mathrm{~h}$ at an electrode constant current of $300 \mathrm{~mA}$. The proteins in the gel were transferred onto a nitrocellulose membrane (Kexing Co., Beijing, China), blocked for $1 \mathrm{~h}$ at $37^{\circ} \mathrm{C}$ in $5 \%$ skim milk powder, and incubated overnight at $4{ }^{\circ} \mathrm{C}$ with sheep anti-rat TGF $\beta 1$ (ab208466; Abcam, Cambridge, UK) and Smad7 (66,478; Proteintech, Wuhan,China) antibodies [25]. Horseradish peroxidase-labeled rabbit anti-sheep secondary antibody was added (1:400; Nakasugi Jinqiao Co., Beijing, China) and incubated at $37{ }^{\circ} \mathrm{C}$ for $1 \mathrm{~h}$. The signal was detected using the enhanced chemiluminescence reagent (Abcam). Positive bands were analyzed using Gel-Pro 4.0 gel optical density analysis software, and the cumulative optical density (IOD value) was measured, with the $\mathrm{R}$ value representing the relative protein content as follows: $\mathrm{R}=$ reference IOD value of PLSCR (target)/reference IOD value of GAPDH (reference protein).

\section{Cell culture and RNA interference}

A renal epithelial cell line (MDCK cells, CCL34, passages 53-90; ATCC, Manassas, VA, USA) was grown in Dulbecco's modified Eagle medium supplemented with antibiotics (100 U/mL penicillin, $100 \mathrm{mg} / \mathrm{mL}$ streptomycin; Life Technologies, Carlsbad, CA, USA) and $10 \%$ fetal bovine serum (Life Technologies Co.) at $37{ }^{\circ} \mathrm{C}$ in a $5 \% \mathrm{CO}_{2}$ atmosphere and subcultured with $0.25 \%$ trypsin and $1 \mathrm{mM}$ ethylenediaminetetraacetic acid (Life Technologies Co., CA, USA). The cells were treated with $\mathrm{CaOx}(0.5 \mathrm{mM}$; Sigma-Aldrich, St. Louis, MO, USA) for $2 \mathrm{~h}$ and with $0.5 \mathrm{mM} \mathrm{CaOx}$ and $100 \mu \mathrm{g} / \mathrm{mL}$ neutralizing anti-TGF- $\beta 1$ antibody (R\&D Systems, Minneapolis, MN, USA) for $2 \mathrm{~h}$. All experiments were performed in triplicate.

To determine the role of PLSCR in PS eversion, renal tubular epithelial cells were transfected with PLSCR siRNA [26]. siRNA was designed and synthesized by Anhui General Biological System (Anhui, China; see Table 1). Lipofectamine ${ }^{\mathrm{TM}} 2000$ (Sunshine Biotechnology Co., Ltd., Shanghai, China) was used for transfection according to the manufacturer's instructions. After

Table 1 siRNA sequences for PLSCR

\begin{tabular}{ll}
\hline siRNA & Sequence $\left(5^{\prime}-3^{\prime}\right)$ \\
\hline si-NC & UUCUCCGAACGUGUCACGUTT \\
siRNA-390 & UGGACAAACAAAACUCACATT \\
siRNA-85 & GGGCCAUCUAGACCUUUUATT \\
siRNA-911 & GGAGAGACCACUAAGAUGUTT \\
\hline
\end{tabular}

$24 \mathrm{~h}$ of transfection, the cells were digested with trypsin, centrifuged at $1000 \times g$ for $5 \mathrm{~min}$, washed twice with PBS, and centrifuged again. The supernatant was discarded, and the pellet was suspended in PBS to form a single-cell suspension of density $1 \times 10^{6}$ cells $/ \mathrm{mL}$. The positive rate of FAM (carboxyfluorescein) expression was $93 \% \pm 5 \%$ as determined by flow cytometry. To further assess the relationship between TGF $\beta 1$ and PLSCR, the cells were treated with $0.5 \mathrm{mM} \mathrm{CaOx}$ or $10 \mathrm{ng} / \mathrm{mL}$ TGF- $\beta 1$ for $2 \mathrm{~h}$, and subsequently transfected with PLSCR siRNA.

\section{Measurement of PLSCR level in renal tubular cell membranes by western blotting}

Protein was extracted using a natural membrane protein extraction kit ProteoExtract (Chemical Book Co., Beijing, China), and the protein concentration was determined using a Bio-Rad protein assay kit (Noble-Ryder Co., Beijing, China). Subsequently, $40 \mu \mathrm{g}$ of protein was loaded on an $8 \%$ SDS-polyacrylamide gel (stacking gel $100 \mathrm{~V}$, resolving gel $200 \mathrm{~V}$ ) for $1 \mathrm{~h}$ at a constant current of $300 \mathrm{~mA}$. Proteins in the gel were transferred onto a nitrocellulose membrane (Kexing Co., Shenzhen, China) and blocked with 5\% skim milk for $1 \mathrm{~h}$ at $37{ }^{\circ} \mathrm{C}$ and incubated overnight at $4{ }^{\circ} \mathrm{C}$ with sheep anti-rat PLSCR monoclonal antibody (1:200, PAB781Hu01; Abcam, Guangzhou, China). Horseradish peroxidase-labeled rabbit anti-sheep secondary antibody was then added (1:400) and the mixture was incubated at $37^{\circ} \mathrm{C}$ for $1 \mathrm{~h}$. After washing the membrane, the signal was detected with enhanced chemiluminescence reagent (Abcam, Guangzhou, China). Positive bands were analyzed using Gel-Pro 4.0 gel optical density analysis software, and the IOD value was measured, with the $R$ value representing the relative protein content as described above.

\section{Measurement of membrane phosphatidylserine distribution}

The amount of cell membrane PS eversion was determined using the fluorescence quenching method described by Kim et al. [27] and our research team [2], with nitrobenz2-oxa-1,3-diazole (NBD, Shanghai, China) as the fluorescence probe. After labeling the PS in the outer layer of the cell membrane with NBD, the cells were cultured in PBS containing $5 \mathrm{mM}$ diisopropylfluorophosphate. Thereafter, PBS containing calcium oxalate $(1.0 \mathrm{mM})$ was added and the cells were incubated at $37^{\circ} \mathrm{C}$. An equal amount of cell suspension was discharged every $10 \mathrm{~min}$, and the fluorescence intensity was recorded using an RF-5000 spectrofluorometer (Shimadzu, Kyoto, Japan). The settings of the spectrofluorometer were as follows: $10 \mathrm{~nm}$ slit width for an emission wavelength of $530 \mathrm{~nm}$; and $5 \mathrm{~nm}$ slit width for an excitation wavelength of $470 \mathrm{~nm}$. Next, the average 
fluorescence value (FT) was recorded over $50 \mathrm{~s}$. The average reduced fluorescence intensity (FD) was also recorded after using a dithionite solution to quench the NBD fluorescence from the outer layer of the cell. Thereafter, $1 \%(\mathrm{w} / \mathrm{v})$ Triton $\mathrm{X}-100$ was added to permeabilize the cell membrane. The NBD fluorescence from the inner layer of the cell membrane was then quenched, and the fluorescence intensity (F0) was recorded. The percentage of NBD-PS in the inner lobules was later calculated using the following equation: percentage of internalized NBD-PS $=100 \times[(\mathrm{FD}-\mathrm{F} 0) /(\mathrm{FT}-\mathrm{F} 0)]$.

The percentage of PS externalization was determined according to the principle used for the measurement of NBDPS internalization. The percentage of NBD-PS in the outer lobules was also calculated using the following equation: percentage of NBD-PS in outer lobules $=100 \times[(\mathrm{FT}-\mathrm{FD}) /$ (FT-F0)].

\section{Statistical analysis}

Continuous variables are expressed as mean \pm standard deviation. A non-parametric paired rank-sum test, $t$-test, and chi-square test were used. All analyses were performed using SPSS software 19.0 (SPSS, Inc., Chicago, IL, USA). Results with $P<0.05$ were considered statistically significant.

\section{Results}

\section{TGF- $\beta 1 /$ Smad signaling stimulates PS externalization in vivo}

\section{Crystal formation in renal tissue of rat model}

To establish a rat model of early stage kidney stone formation, ethylene glycol and ammonium chloride were administered to the stomach of rats for 2 weeks, and then each kidney section was examined with a digital microscope. In the control group specimens, normal renal tubular structures were observed without crystal formation on day 14 (Fig. 1A). When the kidney tissue from the kidney stone group was observed by microscopy, the renal tubules appeared dilated with visible microcrystals; occasional accumulation of $\mathrm{CaOx}$ crystals was observed in some renal tubules, indicating successful establishment of a rat model of early stage kidney stone formation and the generation of renal tubule cell injury.

\section{Presence of PS in the renal tubular cell membrane}

Annexin V-FITC, a fluorescent molecule that binds to PS on the cell surface, is widely used to detect PS redistribution. In our study, MDCK cells in the normal control, kidney stone, and kidney stone + SB431542 groups were observed under a confocal laser microscope (Fig. 1B). The PS-eversion rate increased in the kidney stone group compared with that in the control group $(P<0.05$, Fig. $1 \mathrm{C}, \mathrm{D})$, whereas cells in the kidney stone + SB431542 group showed a lower basal level of PS externalization than those in the kidney stone group $(P<0.05$, Fig. 1C, D $)$.

\section{Measurement of TGF- $\beta 1$ and Smad7 levels}

The TGF- $\beta 1$ level in the kidney stone group was quantified by western blotting. A typical western blot is shown in Fig. 2A together with the densitometric analysis of the TGF$\beta 1$ level. Values were normalized to those of the control and expressed as the ratio of TGF- $\beta 1$ to tubulin. The addition of ethylene glycol and $\mathrm{NH}_{4} \mathrm{Cl}$ significantly increased the TGF- $\beta 1$ level and decreased the Smad7 level compared with those in the control cells (Fig. 2A); however, treatment with SB431542 + ethylene glycol and $\mathrm{NH}_{4} \mathrm{Cl}$ led to significantly decreased TGF- $\beta 1$ level and increased Smad7 level compared with those in cells treated with ethylene glycol and $\mathrm{NH}_{4} \mathrm{Cl}$.

\section{TGF activates PLSCR activity in the renal tubule cell membrane in vitro}

\section{PLSCR}

The level of PLSCR was evaluated by western blotting. The cells were treated with $\mathrm{CaOx}$ for $2 \mathrm{~h}$. The PLSCR level was negligible in control cells but significantly increased in the $\mathrm{CaOx}$ group $(P<0.05$, Fig. 2B). PLSCR overexpression was inhibited following treatment with the anti-TGF- $\beta 1$ antibody. After the transfection of cells in the TGF- $\beta 1$ and $\mathrm{CaOx}$ groups with PLSCR siRNA, PLSCR expression significantly reduced $(P<0.05$, Fig. 2B).

\section{Impaired NBD-PS inward movement}

We determined inward and outward movements of PS in the renal tubular epithelial cell membrane to evaluate the PLSCR activity. To assess whether PLSCR influences the movement of PS from the outer leaflet to the inner leaflet of the plasma membrane, we integrated fluorescently labeled PS (NBD-PS) into the outer leaflet of plasma membrane and monitored its internalization (Fig. 3). The amount of NBDPS internalized by MDCK cells in the control and $\mathrm{CaOx}$ groups was approximately $46.2 \%$ and $17.8 \%$, respectively. Hence, the rate of PS internalization in the $\mathrm{CaOx}$ group cells was significantly lower than that in control group cells $(P<0.01$, Fig. 3A). However, the level of internalized NBD$\mathrm{PS}$ in the anti-TGF- $\beta 1+\mathrm{CaOx}$ group increased to $34.2 \%$, which was significantly higher than that in the $\mathrm{CaOx}$ group $(P<0.01$, Fig. 3A). After the transfection of cells in the 
A

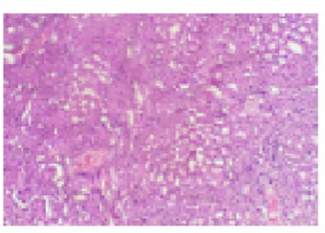

Control

B

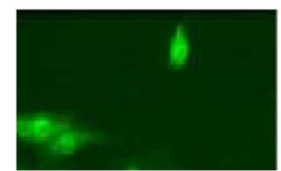

Control

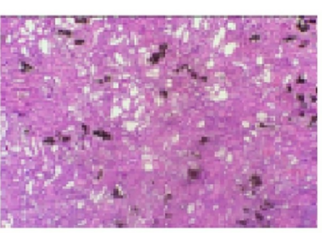

Kidney stone

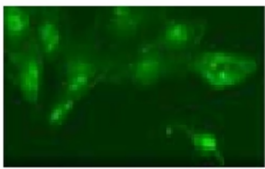

Kidney stone

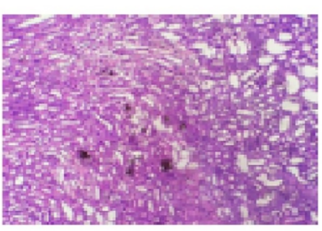

Kidney Stone+SB432542

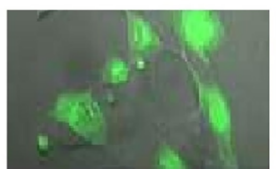

Kidney stone+SB432542
C

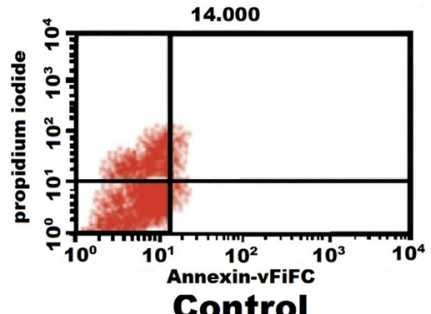

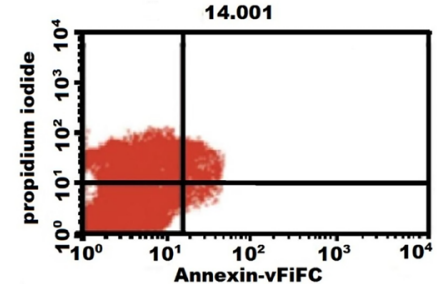

Kidney stone

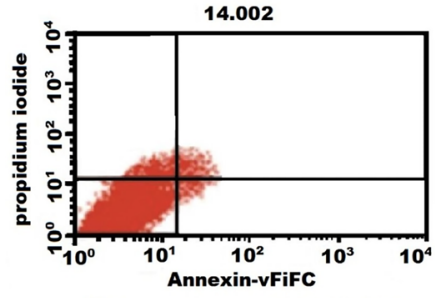

Kidney stone+SB432542
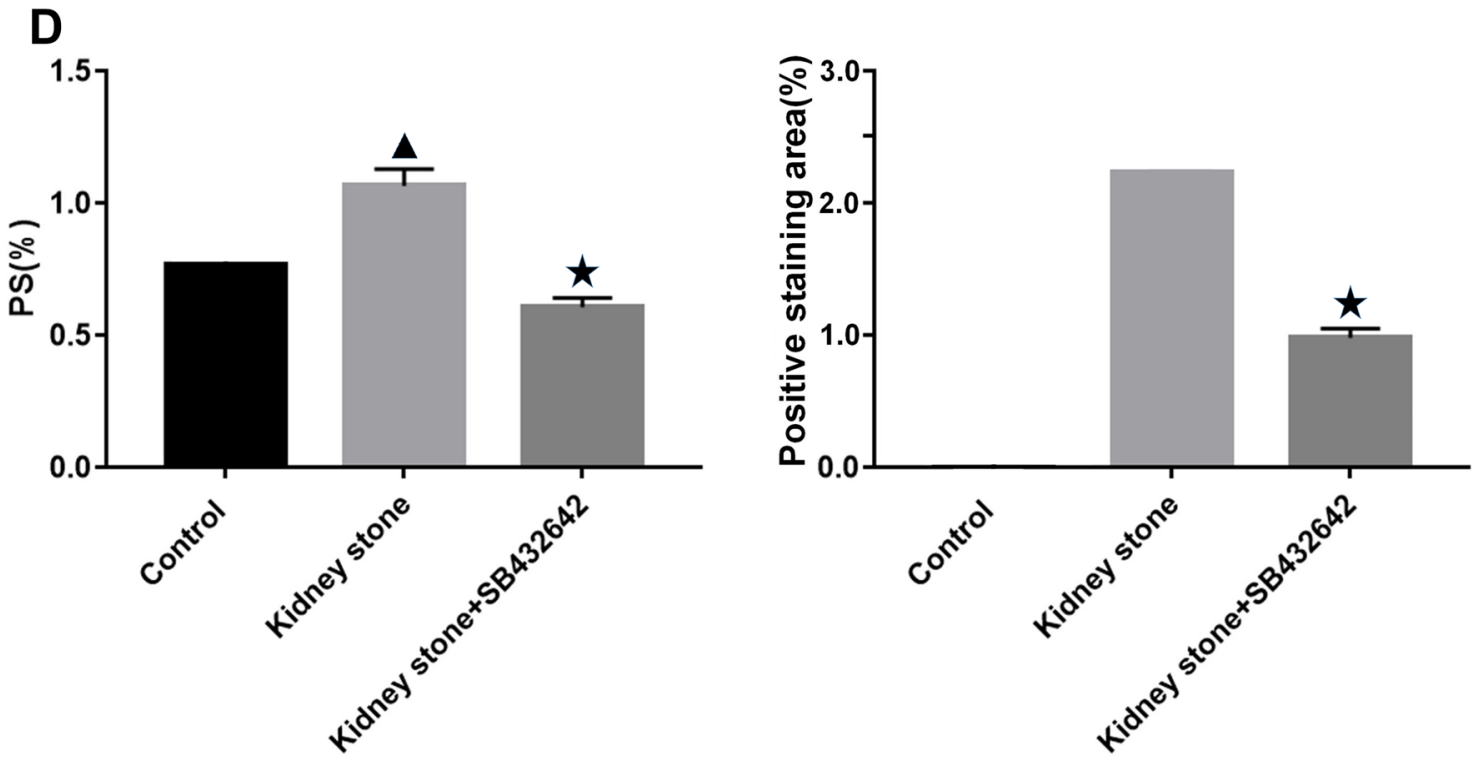

Fig. 1 Crystal formation and PS externalization observed in the control, kidney stone, and kidney stone + SB431542 groups. (A) Crystal formation in the renal tissue on day 14; arrow indicates microcrystalline structures. (B) MDCK cells observed by confocal laser

TGF- $\beta 1$ and $\mathrm{CaOx}$ groups with PLSCR siRNA, the level of internalized NBD-PS significantly increased $(P<0.05$, Fig. 3B, C).

microscopy. (C) Flow cytometric plots of eversion rate. (D) Eversion rate (\%). Triangle indicates $P<0.05$ vs. control. Asterisk indicates $P<0.05$ vs. kidney stone group

\section{Enhanced NBD-PS outward movement}

To determine whether PS outward transport is affected by oxalate, MDCK cells were intracellularly labeled with 

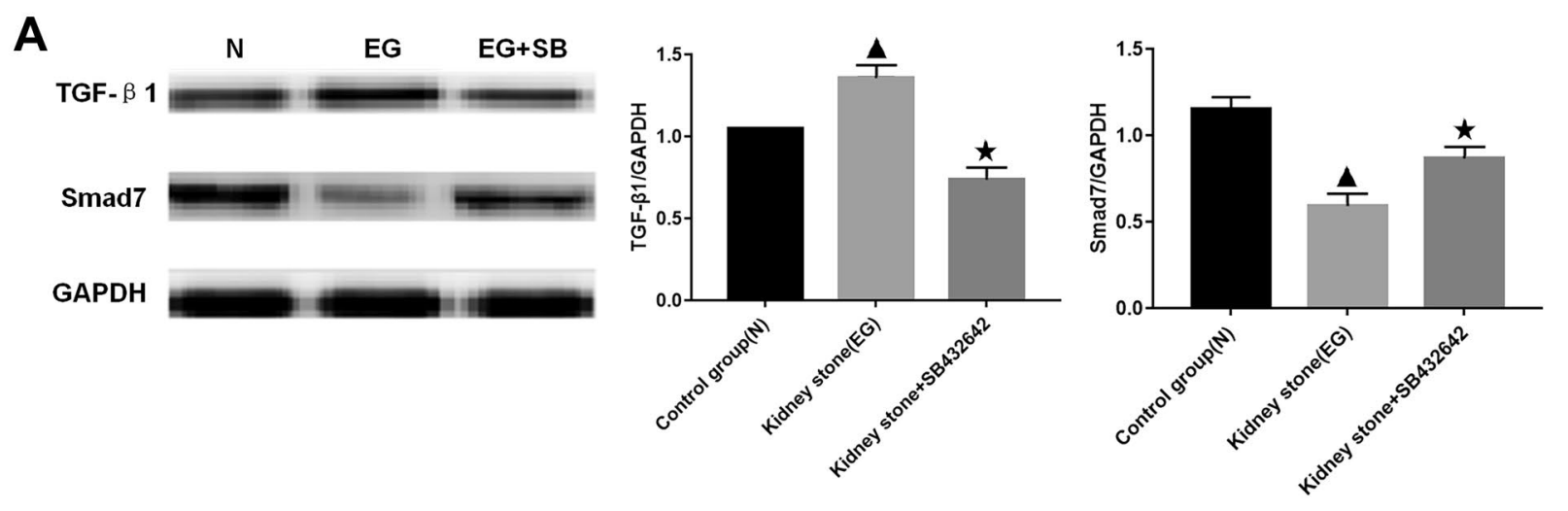

B
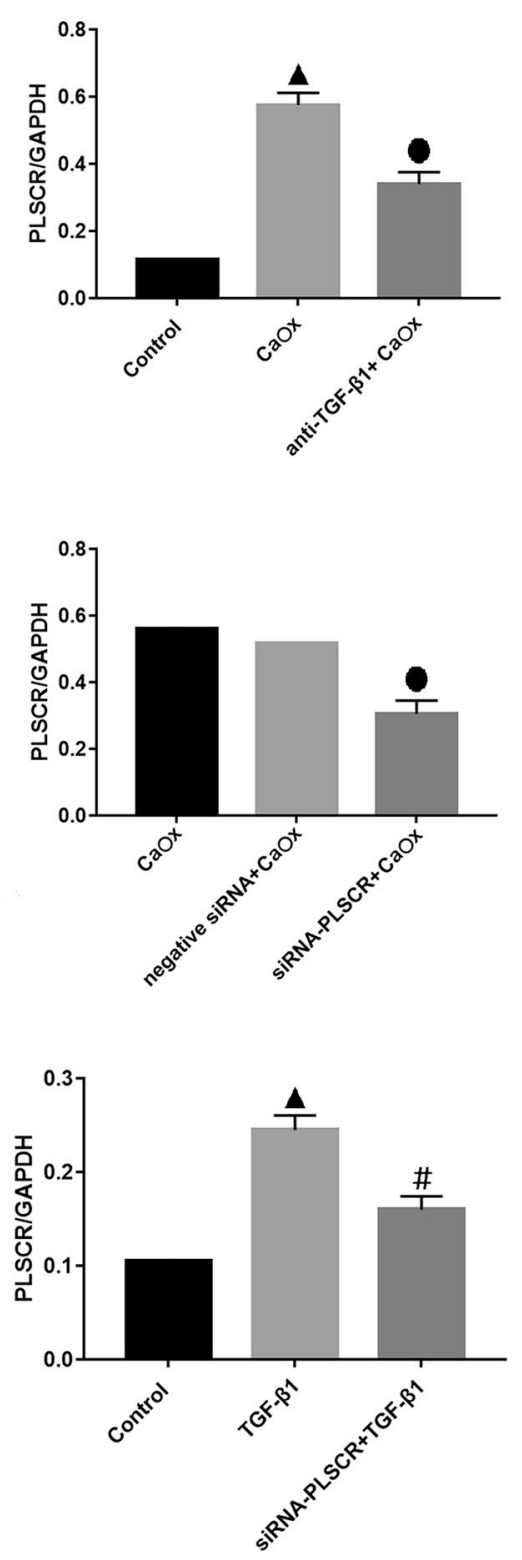
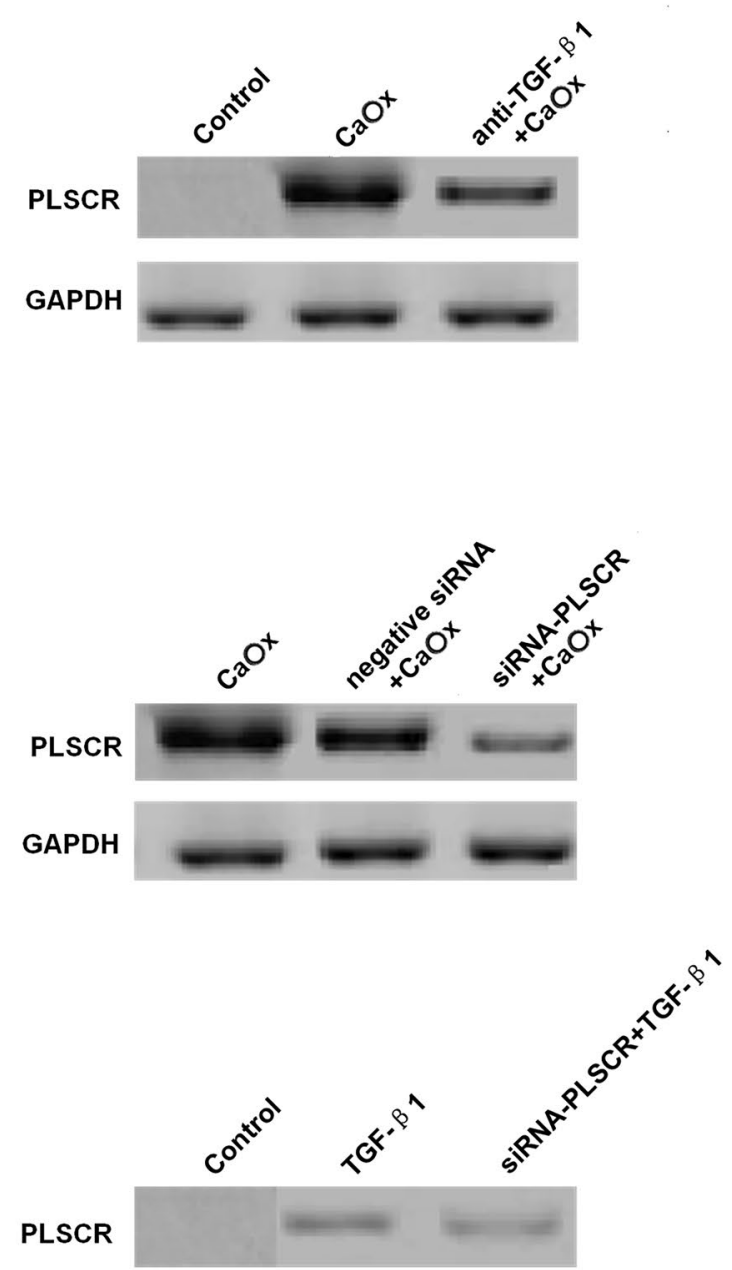

GAPDH 
4Fig. 2 TGF- $\beta 1 /$ Smad expression in the control, kidney stone, and kidney stone + SB431542 groups, and PLSCR expression in the renal tubule cell membrane. (A) TGF- $\beta 1 / \mathrm{Smad}$ expression. (B) Relative phospholipid scramblase (PLSCR) levels, and representative blot with expression normalized to that of GAPDH. $P<0.05$. Triangle indicates $P<0.05$ vs. control. Round dot indicates $P<0.05$ vs. $\mathrm{CaOx}$ group. Pound sign indicates $P<0.05$ vs. TGF- $\beta 1$ group

NBD-PS, and the extent of its movement to the exoplasmic leaflet was determined. Incubation medium contained bovine serum albumin $(1 \% \mathrm{w} / \mathrm{v})$, which rapidly extracted surface-expressed NBD-PS. Approximately $34.5 \%$ of NBDPS migrated to the outer leaflet in control cells, whereas the rate of outward PS transfer in the $\mathrm{CaOx}$ group cells was increased to $75.3 \%$ compared with that of the total inner labeled NBD-PS, which was significantly greater than that in control group cells $(P<0.01$, Fig. 3A). To determine whether TGF- $\beta 1$ causes PS eversion in renal tubule cell membranes by activating PLSCR, cells in the TGF- $\beta 1$ and $\mathrm{CaOx}$ groups were transfected with PLSCR siRNA. After PLSCR siRNA transfection, the externalization rate was lower than that in the TGF- $\beta 1$ and $\mathrm{CaOx}$ groups $(P<0.01$ for both, Fig. 3B, C).

\section{Discussion}

To date, animal studies have neither focused on the role of PS in kidney stone formation nor addressed whether the findings of in vitro studies translate to those in animals. To obtain more reliable results, studies using in vitro models are preferable. In our rat model of early stage $\mathrm{CaOx}$ stones, the TGF- $\beta 1$ level and PS-eversion rate in the kidney stone group increased, which is consistent with the results obtained at the cellular level, showing that with increased oxalic acid concentration, a concomitant increase in cell membranePS eversion allows crystals to adhere to the cell membrane [28]. Thus, we confirmed that the above cytological studies are suitable for examining the rat model. We found that oxalate itself is injurious to cells and that it may serve as a primary agent to upregulate TGF- $\beta 1$. Furthermore, the TGF$\beta 1$ level and PS externalization were substantially inhibited by SB 431542 , suggesting that the TGF- $\beta 1 /$ Smad signaling pathway facilitates increased PS externalization at the organism level. Progressive activation of NAD(P)H oxidase in renal tubular cells via the induction of TGF- $\beta 1$, is a potential molecular mechanism of TGF- $\beta 1 / \mathrm{Smad}$ signaling-induced ROS production [7], whereas ROS mediated accumulation of MRP-1 or BCRP plays a key role in oxalate-induced PS externalization in the renal epithelial cell membrane [23]. Therefore, we conclude that the mechanism of TGF- $\beta 1 /$ Smad signaling-induced PS eversion in renal tubular epithelial cells is mediated via oxidative stress caused by ROS.
When LLC-PK1 cells were treated with 1 mmol potassium oxalate (KOx) for $6,12,24$, or $48 \mathrm{~h}$, Khan et al. did not detect significant apoptotic morphological changes in the cells after $6 \mathrm{~h}$ of oxalate treatment. However, after $12 \mathrm{~h}$ of exposure, they observed significant apoptotic changes including condensation and margination of nuclear chromatin, DNA fragmentation, and PS migration in the plasma membrane bilayer from inside to the cell surface [8]. In our previous study, we showed that $0.5 \mathrm{mmol}$ oxalate caused a time- and concentration-dependent increase in PS externalization in the MDCK renal epithelial cell line [2]. In this study, $0.5 \% \mathrm{CaOx}$ was applied to the cells, and the PS-eversion rate increased in the kidney stone group. Although the cell membrane PS turned over in our present study, these cells should not have undergone apoptosis. PS eversion is an important surface marker of apoptosis. Recent studies have shown that apoptosis and PS eversion are two independent events, that is, apoptotic cells do not necessarily show PS eversion and PS-eversion cells are not necessarily apoptotic [29]. It is not appropriate to rely only on PS eversion to determine whether a cell is apoptotic, because studies have reported PS exposure in non-apoptotic cells [30-32].

In this study, negligible level of PLSCR was detected in control group cells, whereas this protein was significantly increased in the $\mathrm{CaOx}$ group, indicating overexpression of PLSCR. These results are consistent with the findings of Singireesu et al. regarding the potential toxic effects of DHCL on kidney cells [33]. When cells in the CaOx group were treated with anti-TGF- $\beta 1$ antibody, the level of PLSCR was significantly lowered, indicating that the activation of PLSCR was mediated by TGF- $\beta 1$. In addition, we observed enhanced outward movement of NBD-PS in the TGF- $\beta 1$ group and $\mathrm{CaOx}$ group. When renal tubular epithelial cells from these groups were transfected with PLSCR siRNA, the PS internalization rate increased, whereas the externalization rate decreased, indicating that TGF- $\beta 1$ causes PS externalization in the renal tubule cell membrane by activating PLSCR in the renal tubule cell membrane in vitro. Taken together, oxalate exposure to renal tubule cells induces TGF$\beta 1$ expression, resulting in increased ROS production via NAD(P)H oxidase; ROS then alters the activity of PLSCR $[9,10]$. Finally, PLSCR leads to PS externalization in the renal tubule cell membrane, as demonstrated in our study.

A previous study suggested that oxalate treatment does not activate PLSCR in MDCK cells in vitro, as PLSCR activation requires increased cytoplasmic $\mathrm{Ca}^{2+}$, and oxalate rapidly decreases the intracellular $\mathrm{Ca}^{2+}$ concentration in MDCK cells [2]. This hypothesis is supported by the results of the present study. That is, although the previous study demonstrated the effects of oxalic acid, rather than $\mathrm{CaOx}$, on renal tubular epithelial cells, we found that the $\mathrm{Ca}^{2+}$ concentration increased in the renal collecting system during the early stage of $\mathrm{CaOx}$ stone development in a rat model. As PLSCR 
Fig. 3 Rate of inward and outward movements of NBDPS. (A) Comparison among the control, oxalate calcium, and anti-TGF- $\beta 1$ + oxalate calcium groups. (B) Comparison among the calcium oxalate, negative + calcium oxalate, and siRNA-PLSCR + calcium oxalate groups. (C) Comparison among the control, TGF- $\beta 1$, and siRNA-PLSCR + TGF-

$\beta 1$ groups. Triangle indicates $P<0.05$ vs. control. Round dot indicates $P<0.05$ vs. $\mathrm{CaOx}$ group. Pound sign indicates $P<0.05$ vs. TGF- $\beta 1$ group
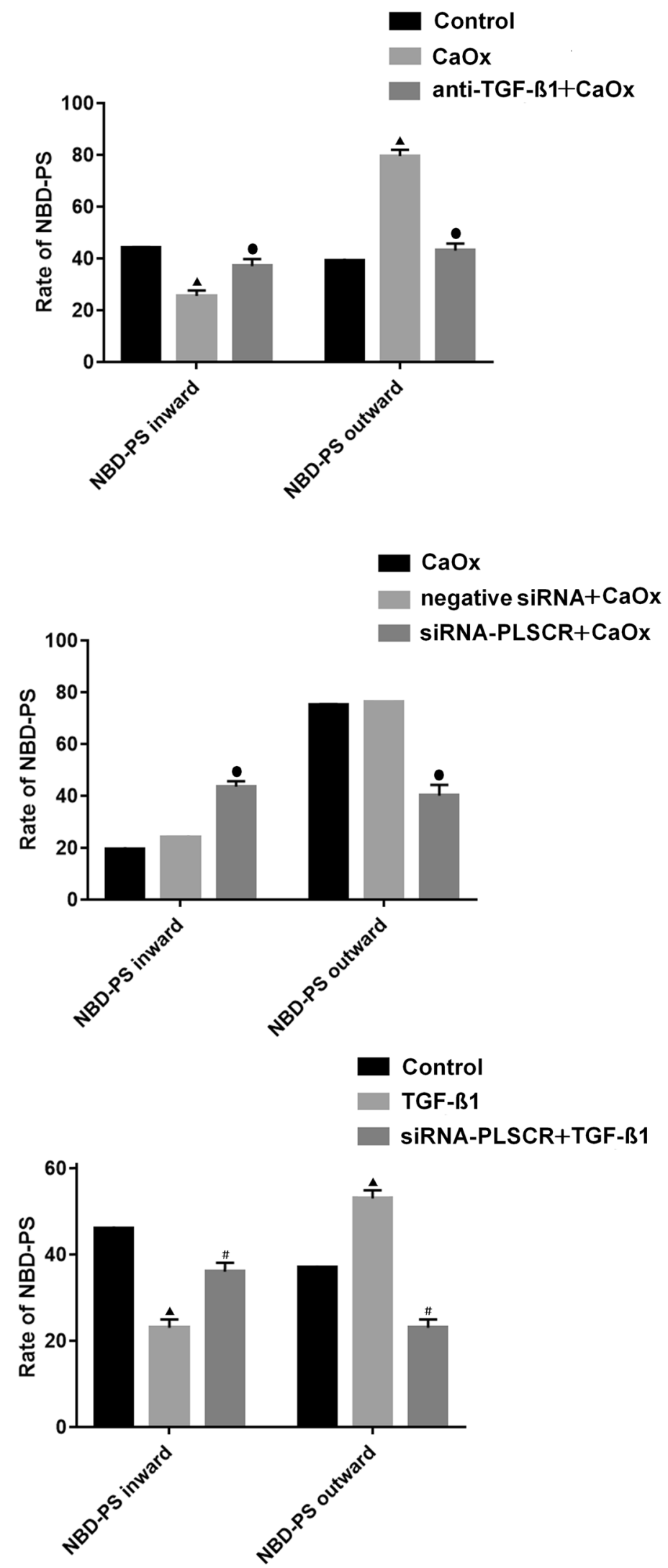
is exposed beyond the cell membrane, we believe PLSCR may be activated by $\mathrm{Ca}^{2+}$ in the renal collecting system rather than by intracellular $\mathrm{Ca}^{2+}$.

Under physiological conditions, an asymmetric distribution of phospholipids in the eukaryotic cell membrane, which requires aminophospholipid translocase (APLT) and PLSCR to play a synergistic role, is necessary for the cell membrane to perform its physiological functions [34]. In this experiment, we considered the ratio of PS eversion in the cell membrane to indicate the activity of PLSCR. Because APLT has been confirmed as one of the factors causing PS eversion, APLT affected the measurement of PLSCR enzyme activity in this experiment. Further clinical studies are required to validate how APLT and PLSCR work together in PS eversion of the renal tubular cell membrane, and to identify other factors controlling PS eversion to better understand the mechanism underlying kidney stone formation.

\section{Conclusions}

$\mathrm{CaOx}$ exposure can potentiate the upregulation of TGF- $\beta 1$, which subsequently activates ROS in renal tubular cells; ROS then strongly activates PLSCR, representing one of the major mechanisms by which TGF- $\beta 1$-ROS signaling stimulates PS externalization in the renal tubule cell membrane during the early stage of kidney stone development. The results of this study form a basis for further detailed research on the development of therapeutic agents that specifically treat urolithiasis and exert fewer adverse effects.

Data availability The datasets generated during and/or analyzed during the current study are available from the corresponding author on reasonable request.

\section{Declarations}

Conflict of interest The authors declare that they have no conflict of interest.

Ethics approval All animal studies were conducted according to the National Institutes of Health Guide for the Care and Use of Laboratory Animals. The experimental procedures were approved by the Animal Experiment Use Ethics Committee of the First Affiliated Hospital of Harbin Medical University (Approval number: 2020005, Harbin, China).

Open Access This article is licensed under a Creative Commons Attribution 4.0 International License, which permits use, sharing, adaptation, distribution and reproduction in any medium or format, as long as you give appropriate credit to the original author(s) and the source, provide a link to the Creative Commons licence, and indicate if changes were made. The images or other third party material in this article are included in the article's Creative Commons licence, unless indicated otherwise in a credit line to the material. If material is not included in the article's Creative Commons licence and your intended use is not permitted by statutory regulation or exceeds the permitted use, you will need to obtain permission directly from the copyright holder. To view a copy of this licence, visit http://creativecommons.org/licenses/by/4.0/.

\section{References}

1. Detsyk O, Solomchak D, Bugro V (2019) Patient pathways as a tool of improvement in management of urgent and scheduled health care for kidney stone disease. Wiad Lek 72:2128-2134

2. Yu SL, Gan XG, Huang JM et al (2011) Oxalate impairs aminophospholipid translocase activity in renal epithelial cells via oxidative stress: implications for calcium oxalate urolithiasis. J Urol 186:1114-1120

3. Zhao YW, Guo D, Li CY, Ouyang JM (2019) Comparison of the adhesion of calcium oxalate monohydrate to HK-2 cells before and after repair using tea polysaccharides. Int J Nanomed 14:4277-4292

4. Jayachandran M, Lugo G, Heiling H, Miller VM, Rule AD, Lieske JC (2015) Extracellular vesicles in urine of women with but not without kidney stones manifest patterns similar to men: a case control study. Biol Sex Differ 24:2

5. Liu Y, Chen S, Liu J, Jin Y, An R (2020) Telmisartan inhibits oxalate and calcium oxalate crystal-induced epithelial-mesenchymal transformation via PPAR- $\gamma$-AKT/STAT3/p38 MAPKSnail pathway. Life Sci 241:117108

6. Han S, Zhao C, Pokhrel G, Sun X, Chen Z, Xu H (2019) Hydroxycitric acid tripotassium inhibits calcium oxalate crystal formation in the Drosophila melanogaster model of hyperoxaluria. Med Sci Monit 25:3662-3667

7. Joshi S, Peck AB, Khan SR (2013) NADPH oxidase as a therapeutic target for oxalate induced injury in kidneys. Oxid Med Cell Longev 2013:462361

8. Khan SR, Byer KJ, Thamilselvan S et al (1999) Crystal-cell interaction and apoptosis in oxalate-associated injury of renal epithelial cells. J Am Soc Nephrol 10:S457-463

9. Schreiber R, Ousingsawat J, Wanitchakool P (2018) Regulation of TMEM16A/ANO1 and TMEM16F/ANO6 ion currents and phospholipid scrambling by $\mathrm{Ca}^{2+}$ and plasma membrane lipid. J Physiol 596:217-229

10. Schreiber R, Buchholz B, Kraus A (2019) Lipid peroxidation drives renal cyst growth in vitro through activation of TMEM16A. J Am Soc Nephrol 30:228-242

11. Clarke RJ, Hossain KR, Cao K (2020) Physiological roles of transverse lipid asymmetry of animal membranes. Biochim Biophys Acta Biomembr 1862:183382

12. Bernhardt I, Nguyen DB, Wesseling MC, Kaestner L (2020) Intracellular $\mathrm{Ca}^{2+}$ concentration and phosphatidylserine exposure in healthy human erythrocytes in dependence on in vivo cell age. Front Physiol 10:1629

13. Nagata S, Sakuragi T, Segawa K (2020) Flippase and scramblase for phosphatidylserine exposure. Curr Opin Immunol 62:31-38

14. Sakuragi T, Kosako H, Nagata S (2019) Phosphorylation-mediated activation of mouse Xkr8 scramblase for phosphatidylserine exposure. Proc Natl Acad Sci U S A 116:2907-2912

15. Yang X, Cheng X, Tang Y et al (2019) Bacterial endotoxin activates the coagulation cascade through gasdermin D-dependent phosphatidylserine exposure. Immunity 51:983-996.e6

16. Yu A, McMaster CR, Byers DM, Ridgway ND, Cook HW (2003) Stimulation of phosphatidylserine biosynthesis and facilitation of uv-induced apoptosis in Chinese hamster ovary 
cells overexpressing phospholipid scramblase1. J Biol Chem 278:9706-9714

17. Liu Y, Chen S, Liu J, Jin Y, Yu S, An R (2020) Telmisartan inhibits oxalate and calcium oxalate crystal-induced epithelial-mesenchymal transformation via PPAR- $\gamma$-AKT/STAT3/p38 MAPKSnail pathway. Life Sci 241:117108

18. Rashed T, Menon M, Thamilselvan S (2004) Molecular mechanism of oxalate-induced free radical production and glutathione redox imbalance in renal epithelial cells: effect of antioxidants. Am J Nephrol 24:557-568

19. Liu YD, Yu SL, Wang R (2019) Rosiglitazone suppresses calcium oxalate crystal binding and oxalate-induced oxidative stress in renal epithelial cells by promoting PPAR- $\gamma$ activation and subsequent regulation of TGF- $\beta 1$ and HGF Expression. Oxid Med Cell Longev 2019:4826525

20. Moraes LC, França EL, Pessoa RS et al (2015) The effect of IFN- $\gamma$ and TGF- $\beta$ in the functional activity of mononuclear cells in the presence of Entamoeba histolytica. Parasit Vectors 8:413

21. Liu Q, Liu Y, Guan X et al (2019) Effect of M2 macrophages on injury and apoptosis of renal tubular epithelial cells induced by calcium oxalate crystals. Kidney Blood Press Res 44:777-791

22. Fong-Ngern K, Vinaiphat A, Thongboonkerd V (2017) Microvillar injury in renal tubular epithelial cells induced by calcium oxalate crystal and the protective role of epigallocatechin-3-gallate. FASEB J 31:120-131

23. Li YF, Yu SL, Gan XG et al (2017) MRP-1 and BCRP promote the externalization of phosphatidylserine in oxalate-treated renal epithelial cells: Implications for calcium oxalate urolithiasis. Urology 7:271.e9-271.e17

24. Zhou QW, Gao FY, Tian D, Liu HR, Wang FX (2019) Inhibition of the TGF- $\beta / S m a d 3$ signaling pathway by SB431542: A study of the intervention effect of SB431542 on silicotic fibrosis in rats. Zhonghua Lao Dong Wei Sheng Zhi Ye Bing Za Zhi 37:801-805

25. Qiu Y, Zhou J, Zhang H et al (2019) Rhodojaponin II attenuates kidney injury by regulating TGF- $\beta 1 /$ Smad pathway in mice with adriamycin nephropathy. J Ethnopharmacol 243:112078

26. Wei C, Qiang Y, Chen C, Gang C, Li S (2014) Influence of silencing PLSCR1 expression with RNA interference on the proliferation and adhesion of colorectal cancer cells. Chin J Oper Proc Gen Surg 8:334-338

27. Kim H, Kim HY, Lee HY, Choi BK, Jang H, Choi Y (2020) A quenched Annexin V-fluorophore for the real-time fluorescence imaging of apoptotic processes in vitro and in vivo. Adv Sci 7:2002988

28. Cao Z, Zhao J, Yang K (2018) Cu-bearing stainless steel reduces cytotoxicity and crystals adhesion after ureteral epithelial cells exposing to calcium oxalate monohydrate. Sci Rep 20:14094

29. Shlomovitz I, Speir M, Gerlic M (2019) Flipping the dogma-phosphatidylserine in non-apoptotic cell death. Cell Commun Signal 17:139

30. Krysko O, De Ridder L, Cornelissen M (2004) Phosphatidylserine exposure during early primary necrosis (oncosis) in JB6 cells as evidenced by immunogold labeling technique. Apoptosis 9:495-500

31. Ferraro-Peyret C, Quemeneur L, Flacher M, Revillard J-P, Genestier L (2002) Caspase-independent phosphatidylserine exposure during apoptosis of primary $\mathrm{T}$ lymphocytes. J Immunol 169:4805-4810

32. Sawai H, Domae N (2011) Discrimination between primary necrosis and apoptosis by necrostatin-1 in Annexin V-positive / propidium iodide-negative cells. Biochem Biophys Res Commun 411:569-573

33. Singireesu SSNR, Mondal SK, Misra S, Yerramsetty S, Babu KS (2018) Dehydrocostus lactone induces prominent apoptosis in kidney distal tubular epithelial cells and interstitial fibroblasts along with cell cycle arrest in ovarian epithelial cells. Biomed Pharmacother 99:956-969

34. Reggio PH (2018) GPCRs moonlighting as scramblases: mechanism revealed. Structure 26:184-186

Publisher's Note Springer Nature remains neutral with regard to jurisdictional claims in published maps and institutional affiliations. 